\title{
Multi-casting in Mountainous Regions of Developing Countries: Analysis through ICT, Institutions, and Capabilities Perspectives
}

\author{
Julian M. Bass \\ Robert Gordon University \\ Aberdeen, UK \\ j.bass@computer.org
}

\author{
Devinder Thapa \\ Luleå University of Technology \\ Luleå, Sweden \\ devinder.thapa@ltu.se
}

\begin{abstract}
Overcoming shortages of teachers or teachers with required skills and experience is a major challenge in rural schools in the global south. We investigate a classroom video conference multi-casting project under development by the Nepal Wireless Networking Project. Our case study draws on one-to-one interviews and focus group discussions from three areas and 10 village research sites in Nepal. An analytical framework which combines the capability approach, institutions theory and ICTs is used. We found that multi-casting projects in the health domain (eHealth projects) focus on capacity building for rural health workers. Despite concerns about the quality of health outreach workers, they were central to eHealth project design. In contrast, teachers were not afforded such a central role in the classroom multi-casting project. Teachers were being sidelined or replaced, rather than being seen as an essential asset to the project. The main contribution of this paper is to enhance understanding of how multi-casting projects can enable or inhibit educational capabilities with regard to health and education in mountainous regions of developing countries.
\end{abstract}

\section{Introduction}

There is a challenging and disturbing gap between urban and rural access to education in developing countries [1]. There are numerous private and public schools in urban areas. However, in the rural areas, even those where public transport is available, we find a few private or public schools. This lack of access is exacerbated in higher altitudes of mountainous regions, where the number of private schools disappears. The few, so called, public schools are mostly run by local communities, and are thinly scattered between different remote larger villages. We can observe a strange negative correlation between altitude and number of schools in mountainous developing countries like Nepal. There are also noticeable differences in pedagogy, syllabus, language of instructions, and skill of teachers besides a lack of infrastructure. The desire for access to improved education institutions is an important factor causing migration from high altitude and rural areas to urban settlements.

ICTs can help to mitigate some of these disparities in access to education [2]. The evidence from our case study in Nepal shows that ICT can play an important role in developing individual as well as collective capabilities in healthcare, education, and business, which can lead to human development [3] [4].

In this paper, we explore an aspect of the ICT and education known as classroom multi-casting. The Nepal Wireless Networking Project (NWNP) has started a distance education initiative using video conference multi-casting. The idea of the multi-casting project is to provide Math, English, and Science education through online video conferencing. In this system, there will be a live internet connection between the mountain villages' rural schools and urban schools. Based on the availability of teachers, in any of these subjects in the selected schools, they will give lectures online. The schools in remote locations can watch and listen to the lecture online; simultaneously, they can ask questions through online chat or audio systems. There will be special functionality provided to the (teacher) administrator to manage the class. The teachers can also use PowerPoint presentation and white boards online.

Regarding technical configuration, the main server of the multi-casting system will reside in Nepal, so that the schools can avoid slow transmission. NWNP is using open source software called 'open meeting' for video conferencing. The NWNP has hired 3 programmers to customize this open source software for the multi-casting. The main customisation was required to host an instance of the open meeting software in NWNP servers. The project has some funding from Japan to install basic wireless hardware, such as routers, hub, and servers. However, the Japanese funding does not support design, development, and implementation of the software. 
Although NWNP has started the multi-casting project, it is still in an early stage.

To understand the process of project deployment and scaling-up the number of schools involved, our study analyses empirical data using an integrated framework of capabilities and institutions proposed by reference [5]. We explore various institutional influences and stakeholder capabilities impacted by the project initiation and implementation. The main contribution of this paper is to enhance our understanding of multi-casting projects in mountainous regions in developing countries that not only lack funding, but also skilled personnel, infrastructure, stable political systems and technology-awareness. The details of the case study and its findings are discussed in the subsequent sections.

The paper is organized into seven sections. After the introduction, section 2 presents the related work. Section 3 presents a theoretical framework. Section 4, describes the research method, Section 5 discusses the findings. Section 6 discusses the theoretical and practical implications. Finally, Section 7 summarizes and concludes the paper with some future research directions.

\section{Related work}

Every parent wants to provide better education to their children regardless of their socio-economic status [1] [6]. The stories of rural communities in general and mountain remote communities in particular, in the context of developing countries are not different. In the least developing countries not only finding better schools, but also getting better education is a difficult job [7]. For example, in the mountain regions of Nepal, there are schools and students, but no teachers. Most of the teachers are not well qualified to teach subjects, such as Math, English, and Science, at the same time, there are no platforms to train them. Difficult geographical configuration is one of the main factors among other socio-economic causes. Because of the poor transportation infrastructure in the mountain villages, students cannot get their text books in time. Therefore, the apparent gap between demand and supply of quality education is one of the main obstacles in development process [8].

Research suggests that ICT can play an important role to fulfill the gap between demand and supply of quality education in the remote mountainous communities of developing countries. The ICTs provide access to information sources; at the same time, they facilitate communication that can also promote the cooperation and collaboration among students and teachers of distance schools [9] [10] [11]. The ICT can also provide an environment for synchronous and asynchronous learning; it also provides cost-effectiveness and pedagogical improvement in education [12] [13]. Studies identified the various challenges while implementing eLearning systems, such as lack of systemic approach to ICT implementation, awareness and attitude towards ICTs, administrative support, technical support, language, transforming higher education, staff development, lack of ownership, and inadequate funds [13] [14] [15]. Similarly, implementation of eLearning systems in developed and developing countries also differs because of socio-cultural context [14].

The traditional online educational technology were mainly one way lecture delivery, recorded audio/video streaming, or Tele-broadcast [10]. One of the missing elements in the traditional approach was interactive classrooms that provide an opportunity to share knowledge, experience and perspective, and considered as a core concept of instructional theories [15] [16]. However, with the evolution of media coverage of Web 2.0 that concentrates on the common applications/services such as blogs, video sharing, social networking and podcasting, a more socially connected Web in which people can interact and share real-time experience is possible [17] [18]. For example, in this system, there can be live internet connection among the schools in the mountain villages and urban schools.

However, because of the multiple challenges in the design, development and implementation of multicasting interactive classroom in the mountainous remote communities of developing countries, it is still a distance dream to them. To explore the challenges and opportunities of the multi-casting project, we conducted a case study of NWNP in a mountain district of Nepal. The idea of the NWNP was initiated in 1989 to provide Internet-based services to create socioeconomic opportunities to the mountain communities.

The project started with minimal wireless technology, home-made antennae, and relay stations that had to be positioned in trees. The project is an example of early grassroots movements to use ICT in rural areas within the context of developing countries. It is making every possible effort to adapt modern technologies to the local context. Despite difficult circumstances, such as lack of government support, lack of funding, lack of technical knowledge, lack of electricity, lack of human capacity, and an unstable political system, the project succeeded in providing Internet-based services to mountain regions. Since 
2003, the NWNP has been fully operational. The NWNP initiated a multi-casting system to provide Math, English, and Science education to students in the remote villages through online and real-time communication. Through this system qualified teachers from the urban schools can lecture online for students in the mountain areas who don't have such teachers.

The focus of this paper is to enhance the understanding on how ICT (multi-casting system), and institutions (stakeholders, community, governmental and non-governmental organizations) interact and influence teachers and students capabilities (opportunities to access better education). We explore how the ICT enables or inhibits the educational development process in the mountain regions. To understand this process we adopted an integrated framework of capabilities and institutions proposed by [5]. The theoretical framework is now discussed.

\section{Capabilities and institutions}

This paper develops an analytical framework that draws on both institutional theory and the capability approach [19] [20]. The novel approach of the analytical framework uses institutional theory to understand the social drivers that may inhibit or enable individuals from taking full advantage of ICT resources for the furtherance of their own lives. The capability approach offers a "bottom-up" perspective where the starting point is consideration of individuals' opportunities to achieve their wants and needs. In contrast, institutional theory takes a "top-down" perspective on the rules and norms used to regulate interactions and transactions in society. These institutional trends can sometimes lead the formation, or dissolution, of organisations.

The capability approach emerged from mainstream development research in the 1980 s and became influential among practitioners [21]. The capability approach has influenced current debates in the global human development agenda; for example through creation of human development indicators [22]. Sen's work has improved our understanding beyond previous development economics work that tended to conflate the abundance of commodities and achievement. The capability approach explores an individual's ability to create capabilities (the freedom to achieve) from commodities (production, transactions, good and services). The term "capability" in ICT for development research has tended to refer to an individual's ability to use technology [23]. In comparison, in the Capability Approach, "capability" refers to the freedom to achieve and accomplish their goals. The Capability Approach views ICT as a type of commodity that is meaningful only in the ways that it enhances human capabilities. This avoids the risk of seeing ICT as intrinsically good, as if the use of technology in itself was a valuable achievement. This view of the Capability Approach focuses on the extent to which technology expands people's ability to determine and realize lives that they value. The capability approach recognises that the social context influences the conversion of commodities to capabilities. We will argue that this social context is best analysed using institutional theory.

Institutional theory investigates how broad social and historical forces, ranging from explicit laws to implicit cultural norms, affect and are affected by the actions of individuals and organisations ([24] pg. 153). Institutional analysis has been advocated for making sense of the context into which IT implementations are embedded [25]. Institutional analysis has also been advocated as a theoretical lens for the ICT4D domain [26].

For institutional theorists, organizations are suspended in a web of institutions; so in effect, organizations inhabit institutions [27]. Organizations are only created by institutions when suitable opportunities emerge in society and are observed. From an institutional perspective, the environment of organizations emphasizes societal rules and beliefs that must be adhered to. Over time these socially prescribed practices begin to be taken for granted and thus institutionalized. Such rules and norms emerge from political or regulatory demands, prescriptions of professional bodies and consultants, or from mimetic activities [28].

The combined approach using institutions and capabilities to understand ICT4D interventions has been proposed in [5]. In this framework, there are positive and negative influences between Capabilities and Institutions along with technologies, as shown in Figure 1.

The positive influences are called exciters and the negative influences are inhibitors. These inhibitors and exciters represent degrees of influence and are not simple binary or Boolean values. These dyadic relationships provide an abstraction that establishes causal relations that help both explanation and prediction.

The analytical framework of [5] comprises three perspectives (1) stakeholder capabilities, (2) institutions and (3) information and communication technologies. In general, the capabilities perspective seeks to enhance the skills and opportunities available 
to stakeholders in an ICT4D project. Here we are seeking ways the project meaningfully enhances human capabilities i.e. stakeholder's freedom to achieve and accomplish their goals. In contrast, the institutions perspective explores rules, values, norms and assumptions that surround the activity. The project may challenge certain institutional assumptions, but only if that is an intended goal. Alternatively, the project may support or strengthen currently existing institutional rules or norms; likewise, the technology perspective focuses on the technical processes, innovations and artefacts of the project.

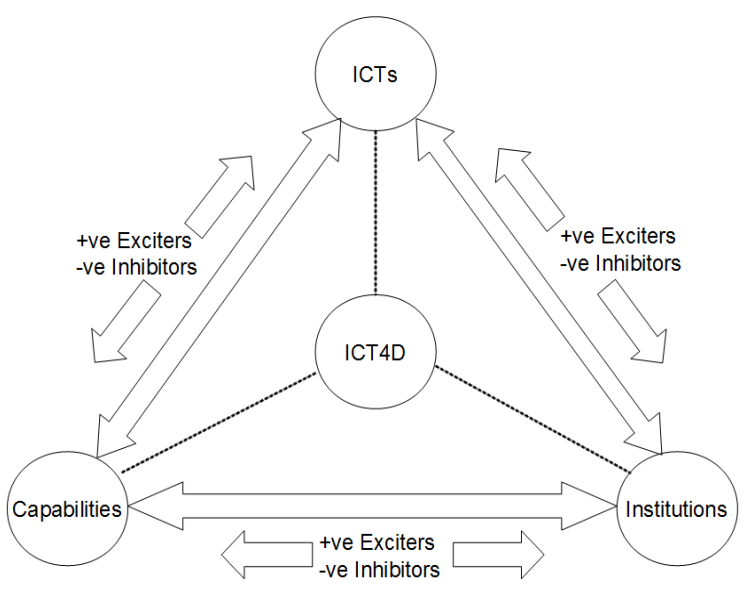

Figure 1. Analytical Framework [5]

Can institutional theory and the capability approach be combined? First, at the level of paradigm, the capability approach was derived from neoclassical economics [29]. Institutional theory is broader and more in use, with two substantial themes: 1) the new institutions school that is also derived from neoclassical economics and 2) the early institutions tradition that emerged from sociology and political science (for example, see the historical review in [19] Chapter 1). The new institutions school shares a focus on markets, competition, and transactional efficiency. Hence, the new institutional branch of institutional theory and the capability approach share neoclassical economics roots and thus are commensurable. Yet both have acquired a considerable and complementary body of research in development and technology-driven change processes.

\section{Research method}

\subsection{Research sites}

This study included research sites in three areas of Nepal: Kathmandu, Hetauda, Chhomrong and ten villages of Myagdi district. The 10 study villages were Nangi, Tikot, Dana, Ghatpo, Sikha, Narjhang, Swantha, Pouder, Khibang, and Kendo. Focus group interviews were conducted in Nangi, Hetauda and Kathmandu districts.

Kathmandu is the capital city of Nepal and as such is an urban location. Government ministries and the NWNP main offices are located in Kathmandu. Kathmandu has seen dramatic population growth, partly due to migration from rural areas and partly since it was relatively safe from violence of the civil war that lasted from $1996-2006$.

Nangi village is in a rural area north east of Pokhara, Nepal's second city. The village has a secondary school and health clinic both largely supported by the local community. There are several income generation projects that provide community finance and provide paid employment that supplements local subsistence farming. Nangi is about 4 hours on foot from a recently constructed dirt road which is seasonally accessible by four wheel drive vehicle. This dirt road is vulnerable to landslides and flooding and is impassible during heavy monsoon rain. When the dirt road is impassible Nangi is about 2 days walk from the nearest metaled road. Chhomrong is also about two days walk from the nearest metaled road, but without the option of a seasonal dirt road. This village is on a popular tourist trek en-route to the mountaineering base camp of the $8,000 \mathrm{~m}$ peak Annapurna I. Currently, a school and simple tourist hotel in the village are connected to the NWNP network infrastructure.

Both rural locations are dominated by subsistence farming with land ownership organized around family groups. Food production comprises small-scale agriculture, horticulture and animal husbandry. Crop selection is determined by altitude creating food production practices that are strictly delimited by horizontal contours. Rice production possible at lower elevations but not at the higher elevations in Nangi or Chhomrong.

\subsection{Data collection}

The data collection was conducted during March 2010, December 2010/January 2011, May 2011 and July 2012. The NWNP has relatively few documentary resources available for inspection. Thus, data collection mainly comprised face-to-face interviews 
with project stakeholders and focus group discussions with (1) classroom teachers and (2) high school students. Project leaders were interviewed formally and informally at the project offices in Kathmandu. Other stakeholders, teachers and students were interviewed at project sites in remote rural locations. The purpose of the project is to use technology to overcome challenging geographical obstacles of high altitude and poor transport and communications infrastructures. Thus, researchers had to overcome these infrastructure limitations and geographical challenges to reach the remote rural project sites.

Interview guides were used to structure the interview discussions. Interviews were open-ended with interviewees given opportunities to raise any issues they felt important. The interviews were recorded and transcribed. The interviews were conducted in English.

\subsection{Data analysis}

The data analysis of this study was guided by the analytical framework discussed in Section 3 (figure 1). For the multi-casting classroom analysis, both the audio interviews and associated written transcripts were carefully reviewed. Following the open coding scheme $[\mathrm{xx}]$, initially key points were identified within the interview data. The key points were mainly focused on understanding how multicasting project enabled or inhibited the educational capabilities of Tele-health workers, teachers and students. Thereafter, the key points were coded and compared within and between interviewees. An iterative data analysis approach was used to refine coding categories. Thus, the key points were combined to create concepts which were then themselves coded, listed and compared within and between interviewees. Concept categorisation was used to organise the data into taxonomy. The findings of this analysis process are now presented below.

\section{Case study and findings}

Nepal is the most mountainous country in the world which is characterised by high mountains, ridges and passes intersected by deep river valleys. The region is subject to substantial and damaging seasonal precipitation leading to large fast-flowing rivers and the propensity for avalanches, landslides and rock falls. This in turn presents challenges for developing transport and telecommunication infrastructures.

The multi-casting initiative is one of several undertaken by the NWNP and previously reported elsewhere [3] [4]. NWNP have extensive experience of tackling the unique geographical obstacles to be found in Nepal. The project works with the national telecommunications operator and mobile phone service providers. The multi-casting project is a technically ambitious many-to-many video conferencing application built on the installed wireless networking infrastructure and open source software, Open Meeting.

\subsection{Current Status}

Since 2003 the NWNP has been fully operational. The project is an example of early grassroots movements to use ICT in rural areas within the context of developing countries. It is making every possible effort to adapt modern technologies to the local context. Despite difficult circumstances, such as lack of government support, lack of funding, lack of technical knowledge, lack of power, lack of human capacity, and an unstable political system, the project succeeded in providing Internet-based services to mountain regions. By 2011, NWNP had already built networks in around 150 villages in Myagdi and other districts. It has also gradually enrolled local, national, and international stakeholders in the formation and extension of the wireless project and its services. The subsequent section explores the NWNP in detail applying the analytical framework.

\subsubsection{Institutions}

Mahabir Pun, Director of NWNP, played an important role in stimulating various formal and informal institutions in the Myagdi district. The NWNP Director had the idea of introducing internet services in the mountain regions. At that time the mountain villages were disconnected from main cities "we had to make two-day trip to the nearest town (pokhara) just to make a phone call or check email" (Director, NWNP, 21/3/2010).

Over time the project extended from one village to another, and started to enrol stakeholders from various non-governmental institutions, such as OLE Nepal, Kathmandu model hospital, and commercial institutions like thamel.com. In 2008

"OLE started to make educational
material for children in the rural areas of
Nepal; however we were not able to
distribute the material to the mountain
regions. NWNP provided the
infrastructure to implement educational
materials in the mountain regions,
whereas OLE, in return, provided
teaching material to schools children.
Therefore, the OLE project is now an


integral part of the NWNP" (Director, OLE, 29/03/2010).

Likewise, in 2008, NWNP initiated a partnership with Om Hospital at Pokhara, Nepal Medical College and Kathmandu Model Hospital to provide eHealth services to various remote communities. The core of the eHealth services consists of web-conferencing equipment installed in the villages as well as in the hospitals, allowing real-time interaction between local health workers and specialist doctors through the video-conferencing services. The health workers of these villages can now communicate with medical doctors in the urban centre of Pokhara and Kathmandu to obtain medical assistance "It is the effort of NWNP to connect the whole Nepal through wireless technology. There are other 3-4 institutions working in telemedicine; we are one of them to provide health related services" (Doctor, Kathmandu Model Hospital, 21/03/2010).

There are other examples where NWNP facilitated various institutions to fulfil their aspirations. For instance, NWNP collaborated with a leading eCommerce organization called Thamel.com who was exploring for business opportunities in mountain regions. In 2008, they conducted a pilot test of virtual ATM machines to operate credit card transaction services for tourist on different trekking routes. They are also planning to start remittance service in remote areas, since many family members from remote communities go to work abroad. Likewise, NWNP lobbied with Nepalese government to introduce liberal license policies since 1997. However,

"this is a pilot study to learn about future possibilities...right now, we are not doing any big things or magic. What we are trying to do simply is to tell that in future those who will not know ICT will be like a blind man. Therefore, we are trying to open their eyes right now... So we cannot say the result of this project will be seen after one or two years. The impact can be seen after 10 or 20 years...the lesson they learned now will be very useful to them in the long run" (Director, NWNP, 21/03/2010).

\subsubsection{Capabilities}

In terms of ICT4D research, the capability approach put emphasis on the contribution technologies may have to increase capabilities of human beings to function in their societies. For example, in addition to providing ICT services there is a need to create social and institutional environment so that poor and needy can access and assess information, build knowledge, and take decisions, in other terms, enhance their basic capabilities. In this particular case, how NWNP builds capabilities of the mountain communities is illustrated as follows.

NWNP has provided easy access to a communication channel that was a previously challenging "People are using Skype and Yahoo! Voice Chat to talk to their relatives in the foreign country, before it was very difficult for us" (Farmer, Nangi Village, 21/03/2010). Students can express their ideas and discuss problems with their teachers. They can collectively identify solutions; something that was once difficult in a face-toface mode because of sociocultural factors

"It helps us in our study. For example, to
understand history, the course book is not
enough. Now, we may download addi-
tional information to get to know more.
It's helping me to receive external in-
formation related to my studies" (Student,
Nangi Village, 23/03/2010).

Capabilities were also enhanced in healthcare through a telemedicine project. The project provided a common platform to bring doctors, health workers, and villagers online, which has increased the villages' collective capabilities with regard to healthcare facilities. Bringing specialist doctors to mountain regions is a difficult task; however, this technology has facilitated community access to doctors even for those living in remote places "Here [Nangi], we have a small clinic where two sisters are working. If they face any difficulties or emergencies, then they connect directly to Kathmandu, or four to five other main hospitals, and consult with the doctors there" (Health Worker, Nangi, 22/03/2010).

Further, the wireless project is collaborating with community people and colleges to run the yak-cow crossbreeding project and Haat Bazar projects. Regarding Haat Bazar an e-Commerce platform

"they [villagers] can use it [Haat Bazaar]
for advertisements in the village. Thanks
to the Internet, we can promote local
products such as Doko, Namlo, Nepali
spices, mushrooms, and cattle. Anyone
who wants to sell their products may use
services like Haat Bazaar on the Net. 
They contact the Internet operator, who will put the information online for other people to see and buy that product" (Director, NWNP, 14/01/2011).

In summary, the study shows that ICT intervention has empowered local communities and enhanced participation in the decision-making process, which is an important dimension of human development.

\subsubsection{ICT Services}

NWNP provide its services to the villages of Myagdi districts through a server in the city of Pokhara. The server is connected to an Internet Service Provider through a fibre connection. From Pokhara, a series of relay stations situated at the top of the eight mountain stations receive/transmit the signals. There are access points at the relay stations to distribute Internet to end-users in these villages. High-speed backhaul radios at the relay stations operate on a dedicated core local-area network (LAN). The villages in each of the network's coverage areas from the relay stations operate on separate local LANs through VLAN switches. Routers at each of the relay stations provide DHCP services to the end-users, and provide interface between the backbone LAN and the locally distributed LANs. The villages connect to the relay stations using point-to-point wireless links. The NWNP uses different sources of power, such as solar, wind, micro hydro generator, and power from main grid line to run the equipment. However, power supply is one of the biggest challenges in extending the ICT services.

Access to the ICT services is provided through desktop computers and laptops. Internet telephony equipment is also connected to make international phone calls. Likewise, telemedicine and distance teaching are done through the high-resolution Polycom network cameras. In its current state NWNP utilizes wireless devices, a network server and associated software, and power generation at the relay stations. The network server in Pokhara facilitates network monitoring and management. The system runs a Fedora Linux distribution with additional third party software. It is configured for maximum redundancy to guard against failure. Linux was chosen due to the large abundance of high quality Open Source software included with the standard distributions and available online. Currently, the NWNP provides the following ICT services: Phone system, community (Nepali) message board and locally hosted home pages for the villages, file sharing, projects on the network, like the
Haat Bazaar trading forum make use of a central database, which is hosted on this system.

\subsubsection{Exciters-Inhibitors}

This section describes how three perspectives capabilities, institutions, and ICT influence and influenced by each other. The findings show that the interaction has positive impact (known as exciters) as well as negative impact (known as inhibitors) in the remote mountain communities.

Institutions-Capabilities: Institutional policies, such as easy license policy to install wireless technology in the mountain region, minimal customs levies on equipment in order to facilitate its adoption throughout the country worked as an exciters to enhance capabilities, whereas, political instability and lack of faith in politicians are major challenges or inhibitors for maintaining and developing capabilities in the mountain villages. Similarly, lack of business models to attract private companies, lack of spending by government on developmental activities of these regions was other institutional inhibitors

"The major challenge for the private
sector is the lack of a business model in
remote places. In the liberal economic
system, a business model is very
important; we have so far not been able
to design the correct sustainable business
model" (Manager, Nepal Tele-
communications Authority, 29/03/2010).

ICT-Capabilities: In terms of how ICT intervention excite/inhibit capabilities, the findings show that community can access to healthcare through telemedicine services, they can access to educational materials through internet, and access to income generating activities, such as Haatbazar, remittance, virtual ATM machine, etc. These ICT services also work as an exciter in promoting tourism and indigenous products. On the other hand, low capabilities in education, for example high illiteracy rate, especially among elderly people, lack of online context based on the Nepalese language is inhibitor that excludes non-English literates from using ICT services. Other inhibitors are lack of skilled manpower to develop NWNP further, shortages of power, and poor ICT infrastructure. Providing power to the wireless equipment at relay is the most challenging tasks for the wireless network operators. It is more challenging during the monsoon time in Nepal because 
there is very little or almost no sunshine for several days. Putting solar power system to run the equipment for 24 hours is the most expensive part of building wireless network in the remote villages of mountain region.

ICT-Institutions: ICT roles in institutional building were also identified. For example, various community groups use NWNP website to organize the cultural activities in the mountain villages. As the villages are scattered around distant geographical regions, the ICT plays an exciters in building social capital through this kind of cultural activities. NWNP also organize computer training to the members of mothers group. The inhibitors in the ICT and institutional interaction are high dependency on key personnel (Mahabir Pun, the NWNP project director), and insufficient physical infrastructure

"it would not be possible without him
[Pun]; still, I haven't found any other
person who has come here to work like
Mahabir. ... We need another person
like him to sustain this project. Without
his presence, this project will not
function properly" (Teacher, Nangi,
23/03/2010).

\subsection{Multi-Casting Project}

The findings discussed in the section 5 are reported from the $\mathrm{PhD}$ study of one of the authors; however, this paper intends to stimulate further discussion on how ICT intervention can enhance capabilities with regard to Tele-Education in health and education. The NWNP, along with an international research team, are currently working on implementing multi-casting classroom to support online teaching. The previous study implies that the multi-casting classroom will promote collaboration and joint teaching activities between schools in the villages as well as between schools in urban and rural areas. International and national collaboration with schools and universities will help teachers to learn from each other. As a result, individual capabilities of school children and teachers will be developed through increased knowledge and competence. Likewise, in the eHealth, multi-casting will empower the local health-worker, particularly, women, and provide opportunity to get access doctor's regular consultation.

This study investigates two video conferencing projects undertaken within the NWNP: tele-health and tele-education. The tele-health project received donor support that enabled purchase of special video- conferencing equipment. In contrast, the multi-casting tele-education project is being developed on a very limited budget.

\subsubsection{Technical Challenges - Health}

The tele-health multi-casting project benefited from donor funding that provided bespoke video conferencing hardware and software. Albeit using the underlying network infrastructure provided by the NWNP team. Thus, in the health project, there were no problems with the video conferencing equipment as such. Rather, there were issues with the reliability, and hence availability, of the underlying network.

Geographical constraints determine that wireless repeaters are located high up, in order to provide lineof-sight interconnections with other transmitters. These elevated locations are isolated and subject to monsoon season shortages of sunlight where wireless repeaters spend contiguous periods lasting several months either in darkness or inside cloud. Solar charging is inhibited, which in turn diminishes storage batteries ability to provide power. These network interruptions can be prolonged "for fairly long time, already few months now, we are not having a connection to Dolakha" (Surgeon, Model Hospital, Kathmandu 17/7/2012).

\subsubsection{Role of Remote Health Workers}

Health workers in remote areas are viewed as a scarce resource to be supported and cherished "it is too difficult to keep health workers in the remote area. Whoever stays there we have to respect" (Surgeon, Model Hospital, Kathmandu 17/7/2012). This is: (1) to avoid patients expressing a preference for a consultation with a city doctor and (2) to provide remote health workers with opportunities for professional development. There is a fear that "patients would say 'oh, Doctor, can I talk to the big doctors in the city?' That's not good"' (Surgeon, Model Hospital, Kathmandu, 17/7/2012). Further "if we are helping the health workers in remote areas then the chances of people getting [access to health] service is high" (Surgeon, Model Hospital, Kathmandu, 17/7/2012).

\subsubsection{Technical Challenges - Education}

The classroom multi-casting project has some specific additional technical challenges beyond those of the tele-health project. The use of proprietary hardware and software solution is too expensive to be scalable to the tele-education project: that "we found that the commercial software that is available in the market is very expensive, there was no way we could afford to buy those equipment and applications" 
(Director, NWNP, 5/7/2012). Thus, an open source software solution was adopted which required some customisation to work on the NWNP network infrastructure, "we were working with university students and also Nepali software engineers who are working in Japan" (Director, NWNP, 5/7/2012).

Schools have been selected by the NWNP that have access to main electricity grids or local microhydroelectric power schemes. This provides relatively reliable electricity supplies for school computer classrooms. However, the challenge of locating wireless repeaters at high elevations is also problematic for the tele-education project.

\subsubsection{Role of Remote Teachers}

The video conferencing tele-education project using multi-casting is designed to overcome a shortage of teachers in rural areas "there is always a shortage of qualified teachers in the schools. So the goal is to put the students in the region in the classroom in different schools and this one qualified teacher teach the classroom" (Director, NWNP, 5/7/2012). The intention is to run live classes "the goal is also to make it two-way communication between the teachers and the students. So, if they have questions they can ask with live interaction" (Director, NWNP, 5/7/2012). The live, real-time, teaching element is seen as important to overcome the limitations of offline eLearning packages that do not offer any interaction with a teacher. The project director did recognise the benefit of teacher continuing professional development. But this acknowledgement seemed at odds with the desire to broadcast lessons from remotely located teachers.

\subsubsection{Multi-Casting Tele-Education Project Status}

Testing the video conferencing application has presented technical challenges. The project team have not been able to develop any virtual network testing infrastructure. Thus, all testing is conducted in realtime using the deployed network infrastructure. The first author was able to observe testing of a video conference connection between Nangi village and Kathmandu. This was one of several such test video conference sessions that had been performed.

\section{Discussion}

\subsection{Implications for Theory}

Theoretically, the objective of this study was to understand how multicasting projects in mountain regions of developing countries can enable or inhibit educational capabilities. Following analytical framework (shown in figure 1), the case study reveals that the project, if implemented as envisaged, might enable the capabilities of tele-health workers, but would inhibit the capabilities of rural and high altitude classroom teachers. This undermining of the role of teacher would threaten the sustainability of the project. ICT4D Projects in general and multicasting project in particular needs to strengthen institutions, build stakeholder capabilities and solve technology problems in order to be sustainable. The analytical lens provided more holistic understanding of the affordances and constraints of ICT when interacting with institutions and capabilities.

\subsection{Implications for practice}

There is a risk that tele-education projects, that seek to enter classroom settings, undermine and marginalise teachers. This threatens the long term sustainability of the projects. Instead, classroom video conferencing projects should focus on teacher skills and capacity building in the same way that the eHealth project supports health outreach workers. This new approach would build strengthening of teacher capabilities into the project. This might be better accomplished by using the video conference multicasting in a continuing professional development role for teachers.

\section{Conclusions}

This research investigates one attempt to overcome teacher skills shortages affecting rural schools in the global south. In geographically challenging environments, such as high altitude areas of Nepal, wireless networking technologies enable Internet connectivity. The Nepal Wireless Networking Project is developing a classroom video conference multicasting system. We have used one-to-one interviews and focus group discussions from visits to three research sites (Kathmandu, Nangi and Chhomrong) to investigate the requirements and design of this teleeducation project.

As a starting point we used an analytical framework which combines the capability approach, institutions theory and ICTs. We found that multi-casting projects in the health domain (eHealth projects) focus on capacity building for rural health workers. Despite concerns about the quality of health outreach workers, they were central to eHealth project design. In contrast, teachers were not afforded such a central role in the classroom multi-casting project. Teachers were being sidelined or replaced, rather than being seen as an essential asset to the project. In terms of our design methodology, the project team is advised to place 
greater emphasis on developing teacher capabilities to enhance its chances of success.

A further data collection field study is envisaged during 2013 that will seek to triangulate the data and analysis research methods used so far.

\section{References}

[1] Brandon D. Lundy and Solomon Negash, 'Teaching Africa: A Guide for the 21st-Century Classroom', Bloomington, Indiana: Indiana University Press, 2013.

[2] T. Unwin, ICT4D Information and Communication Technologies for Development. Cambridge University Press, 2009.

[3] D. Thapa, 'Exploring the link between ICT intervention and human development through a social capital lens: The case study of a wireless project in the mountain region of Nepal', PhD theses in Information Systems, University of Agder, Kristiansand. 2012 Available from http://brage.bibsys.no/hia/handle/URN:NBN:no-bibsys_ brage_33003

[4] D. Thapa, M. K. Sein, \& Ø. Sæbø, 'Building Collective Capabilities through ICT in a Mountain Region of Nepal: Where Social Capital leads to Collective Action', Information Technology for Development, vol. 18, no. 1, pp. 5-22, 2012.

[5] J. M. Bass, B. Nicholson \& E. Subrahmanian, 'A Framework using Institutional Analysis and the Capability Approach in ICT4D', Information Technologies and International Development, vol. 9, no. 1, pp. 19-35, 2013.

[6] S. Kristiansen and Pratikno, 'Decentralising education in Indonesia', International Journal of Educational Development, vol. 26, no. 5, pp. 513 - 531, 2006.

[7] H. Bajracharya, \& W. Brouwer, 'A narrative approach to science teaching in Nepal', International Journal of Science Education, vol. 19, no. 4, pp. 429-446, 1997.

[8] S. Gulati, 'Technology-Enhanced Learning in Developing Nations: A Review', International Review of Research in Open and Distance Learning, vol 9, no. 1, pp. 1-16, 2008.

[9] G. Dhanarajan, 'Distance Education: Promise, performance and potential', Open Learning: The Journal of Open, Distance and e-Learning, vol. 16, no. 1, pp. 61-68, 2001.

[10]D. Eastmond, 'Realizing the promise of distance education in low technology countries', Educational Technology Research and Development, vol. 48, no. 2, pp. 100-111, 2000.

[11] S. S. Rao, 'Bridging digital divide: Efforts in India', Telematics and Informatics, vol. 22, no. 4, pp. 361-375, 2005.

[12] J. M. Pullen \& C. Snow, 'Integrating synchronous and asynchronous internet distributed education for maximum effectiveness', Education and Information Technologies, vol. 12, no. 3, pp. 137-148, 2007.

[13] A. S. Sife, E. T. Lwoga \& C. Sanga, 'New technologies for teaching and learning: Challenges for higher learning institutions in developing countries', International Journal of Education and Development using Information and Communication Technology (IJEDICT), vol. 3, no. 2, 2007.

[14] A. Andersson \& $\AA$. Grönlund, 'A Conceptual Framework for E-learning in Developing Countries: A Critical Review of Research Challenges', The Electronic Journal on Information Systems in Developing Countries, vol. 38, no. 8, pp. 1-16, 2009.

[15]M. Sehrt, 'Digital Divide into Digital Opportunities', [Article]. UN Chronicle, vol. 40, no. 4, pp. 45-46, 2003.

[16] D. Zhang, J. L. Zhao, L. Zhou \& J. Jay F. Nunamaker, 'Can e-learning replace classroom learning?', Commun. $A C M$, vol. 47, no. 5, pp. 75-79, 2004.

[17] P. Anderson, 'What is Web 2.0? Ideas, technologies and implications for education', 2007, Retrieved 27, Dec. 2012, from http://www.jisc.ac.uk/media/documents/ techwatch/tsw0701b.pdf

[18] S. G. Deshpande \& H. Jenq-Neng, 'A real-time interactive virtual classroom multimedia distance learning system', IEEE Trans. Multimedia, vol. 3 no. 4, pp. 432-444, 2001.

[19] W. Richard Scott, 'Institutions and Organizations: Ideas and Interests', 3rd ed. Thousand Oaks, California: Sage Publications, Inc, 2008.

[20] A. K. Sen, 'Development as freedom', New York: Knopf Press, 1999.

[21] A. K. Sen, 'Well-being, agency and freedom: The Dewey Lectures 1984', The Journal of Philosophy, vol. 82, pp. 169-221, 1985.

[22] United Nations Development Programme (UNDP), 'Human development report 1990', 1990, New York: UNDP. Retrieved from http://hdr.undp.org/en/reports/ global/hdr1990

[23] Y. Zheng, 'Different Spaces for e-Development: What Can We Learn from the Capabilities Approach?', Information Technology for Development, vol. 15 no. 2, pp. 66-82, 2009.

[24] W. J. Orlikowski \& S. Barley, 'Technology and institutions: What can research on information technology and research learn from each other?', MIS Quarterly, vol. 25, no. 2, pp. 145-165, 2001.

[25] J. L. King, V. Gurbaxani, K. L. Kraemer, F. W. McFarlan, K. S. Raman \& C. S. Yap, 'Institutional factors in information technology innovation', Information Systems Research, vol. 5, no. 2, pp. 139169, 1994.

[26] C. Avgerou, 'Information systems and global diversity', 2002, Oxford, UK: Oxford University Press.

[27]S. R. Barley \& P. S. Tolbert, 'Institutionalization and structuration: Studying the links between action and institution', Organization Studies, vol. 18, no. 1, pp. 93117, 1997.

[28] P. DiMaggio \& W. Powell, 'Introduction', In W. Powell \& P. DiMaggio (Eds.), The new institutionalism in organisational analysis (pp. 1-38), 1991. Chicago: University of Chicago Press.

[29] A. K. Sen, 'On ethics of economics', 1987, Oxford: Basil Blackwell. 